$\xi=$

\title{
Evaluation of Cathodic Protection Criteria for Embedded Steel Reinforcement in concrete structures
}

\author{
Hirudayasamy Dolli ${ }^{*}$, Andiappan Kavitha ${ }^{2}$ Jeevarose $^{3}$ \\ ${ }^{1,2,3}$ Department of chemistry, \\ Veltechmultitech Dr.Rangarajan Dr.Sakunthala Engineering College, Chennai, India \\ *Corresponding Author Email: ' dolli@veltechmultitech.org
}

\begin{abstract}
This paper presents the results of performance of sacrificial protection in preventing the rebar corrosion in chloride contaminated and chloride free concrete. In this present study, the effectiveness of sacrificial protection of embedded steel rebars has been evaluated on chloride contaminated and chloride free concrete slabs using ribbon type Zinc anodes with ion conductive polymer backfill over a period of 250 days of exposure. The results showed that the ribbon type zinc sacrificial anodes with the navel electrochemical interface (Ion conductive polymer backfill) can confer effective corrosion protection of embedded steel in concrete on preventing corrosion initiation in chloride contaminated as well as chloride free concretes slabs. The cathodic protection criteria evaluated on concrete unit slab showed that $100-150 \mathrm{mV}$ is necessary in the atmospheric exposure and $160-200 \mathrm{mV}$ under alternate wetting \& drying conditions.
\end{abstract}

Keywords: Reinforced Concrete, Sacrificial Protection, Ribbon type Anode, Ion Conductive Polymer Backfill, Sacrificial Anode.

\section{Introduction}

The steel reinforcement bars embedded in concrete structures exposed to marine environment can undergo rapid deterioration due to severe corrosion. The major factor responsible for this accelerated reinforcement corrosion are chloride ingress and breakdown of passivity. It is a global problem affecting the economy of each and every country in the world. A number of corrosion prevention and control system have developed and installed worldwide. Among them, cathodic protection is proven technique, which provides solution lies in maintaining a chloride free environment around the steel reinforcements throughout the service life of the bridges and structures. In other words, cathodic protection (CP) offers fool proof solution to stop the corrosion process[1,2,3].

A number of studies have conducted to evaluate the performance of cathodic protection of steel embedded in prestressed as well as post tensioned concrete structures. Once pitting type corrosion initiated in the active surface of the steel, cathodic protection is best solution to minimize the metal dissolution rate. [4,5]. It is generally achieved using an extended anode laid on the surface of the concrete, either an insoluble anode connected with a current feeder (impressed current cathodic protection) or a more active metal (sacrificial cathodic protection) to stop the corrosion process [6,7].Cathodic protection is an electrochemical process of shifting of potential of steel to the open circuit potential anode thereby the potential difference between the anode and cathode gets minimised and ultimately corrosion process can be stopped [8].
The principle was proved through the laboratory test as well as field scale experiments, which was conducted on the depolarization behaviour and it is reported that the cathodic protection parameters varied with temperature and electrolyte content (water content) [9]. In order to reduce the potential difference between anode and cathode, the steel should be sufficiently polarised towards the open circuit potential of sacrificial anode. The E-Logi test evidently showed that the adequate shifting of (polarisation) steel potential towards cathodic direction [10]. The performance of sacrificial cathodic protection was evaluated on steel rebars embedded in submerged marine piles structure $[11,12,13]$ and reported. The distribution of galvanic current is an important parameter, which is generally obstructed by various factors such as concrete resistivity and anode-cathode steel geometry [14]. On the other hand, it was shown that unless the concrete electrical resistivity is very low, the protection provided by submerged anodes is of limited effectiveness above the water line. So the system requires some special gadgets to regulate the current flow $[15,16]$.The laboratory and field scale experiments have suggested that even current densities lower than $10 \mathrm{~mA} / \mathrm{m}^{2}$ can maintain steel potential values were pitting corrosion cannot initiate when the chloride content exceeds $3.5 \%$ by the weight of cement $[17,18,19]$. Such current densities are necessary consider to design the current requirement for effective corrosion protection. Obviously when the sufficient quantity of galvanic current is applied before corrosion initiated and is maintained throughout the entire service life of the structure. It is also pointed out that the effective performance of any cathodic protection is depends upon the efficient functioning of backfills system at anodeconcrete interface. 
In some practical application of CP systems, hydrogel systems are also developed and the performance is reported[20]. In this paper an attempt has been made to prevent the corrosion of embedded steel in concrete using ribbon type zinc anode in conjunction with ion conductive polymer backfill showed an enhanced corrosion protection even in chloride contaminated concretes.

\section{Experimental}

\subsection{Casting of Experimental Concrete Slabs}

The experimental concrete slabs were cast as per the following standard procedure. The mix proportion as well as the compressive data is presented in Table 1 .

Table 1: Details of Concrete mix proportion and compressive Strength data for experimental specimens

\begin{tabular}{|c|c|c|c|c|c|}
\hline $\begin{array}{l}\text { Sl. } \\
\text { No }\end{array}$ & $\begin{array}{l}\text { Concretemix } \\
\text { design }\end{array}$ & \multicolumn{2}{|c|}{$\begin{array}{l}\text { Compressive } \\
\text { strength } \\
(\mathrm{KN})\end{array}$} & \multicolumn{2}{|c|}{$\begin{array}{l}\text { Concrete resistivity } \\
\text { (K.Ohm.cm) }\end{array}$} \\
\hline 1 & Cement 1part & $\begin{array}{l}\text { M30 } \\
\text { grade }\end{array}$ & $\begin{array}{l}\text { M20 } \\
\text { grade }\end{array}$ & $\begin{array}{l}\text { M30 } \\
\text { grade }\end{array}$ & $\begin{array}{l}\text { M20 } \\
\text { grade }\end{array}$ \\
\hline 2 & $\begin{array}{l}\text { Coarse } \\
\text { aggregate: } \\
1.5\end{array}$ & $32 \pm 2$ & $23 \pm 2$ & $50 \mathrm{~K} . \Omega . \mathrm{cm}$ & $105 \mathrm{~K} . \Omega . \mathrm{cm}$ \\
\hline 3 & $\begin{array}{l}\text { Stone } \\
\text { aggregates } 1.75\end{array}$ & & & & \\
\hline 4 & $\begin{array}{l}\text { Water cement } \\
\text { ratio: } \\
0.48\end{array}$ & & & & \\
\hline
\end{tabular}

The experimental concrete slabs of size $1 \mathrm{mx} 1 \mathrm{mx} 0.1 \mathrm{~m}$ are cast with two numbers of Cold Twisted deformed (CTD) steel rebars of size $16 \mathrm{~mm}$ in diameter, $900 \mathrm{~mm}$ exposed length are derusted in standard pickling solution containing diluted mineral acid $(1: 1 \mathrm{HCl})$ with $5 \%$ hexamine, rinsed in running tap water, air dried, degreased with trichloro ethylene and embedded at a clear cover of $40 \mathrm{~mm}$ from the top surface. Before embedment, the electrical leads were taken from the one end, which is masked with epoxy. After 24 hours, the concrete slabs were subjected to water curing for a period of 28days. Two sets of concrete slabs were cast,

a. Experimental slab cast without chloride (Control system)

b. Experimental slab cast with $3.5 \%$ sodium chloride (Contaminated system)

After a specified period of curing, the concrete slabs were subjected to cathodic protection test using the ribbon type sacrificial anode as detailed below. In the above investigation it is suggested as below.

\subsection{Synthesis of Polymer Backfill}

The poly acrylic acid backfill can be prepared by 0.50 mole $\%$ of poly acrylic acid taken in a $250 \mathrm{ml}$ glass beaker.

Then the 5mole $\%$ of glutaldehyde (gelating agent) is slowly added to the content and dissolved in water. The above content is stirred using a magnetic stirrer for a period of 30minutes. After the specified period, the mineral acid (dopant) is gradually added. To initiate doping, the content is kept in an oven at $75-80^{\circ} \mathrm{C}$ for 2 hours and then it is kept in reduced temperature at $60-65^{\circ} \mathrm{C}$ for 1 hour. At the end of the period, the gel taken out and allowed to air curing. Finally the dried gel can be sliced to any desired size for evaluation Later the product got international patent (US. Patent No. PCTRE /1022 dated 10.12.2006)

\subsection{Installation of Ribbon Type Magnesium Anode and} Evaluation of Cathodic Protection
After a specified period of curing, a ribbon type zinc anode of size $100 \mathrm{~cm}$ long with $1.0 \mathrm{~cm}$ width was laid at the top surface of the concrete. Then a polymer backfill in sheet form of size $100 \mathrm{~cm}$ long with $1.0 \mathrm{~cm}$ wide was inserted in between the anode-concrete surface. The cathodic protection system was energised by electrically connecting the anode and rebar terminals. Before commencement of cathodic protection, the OCP of steel potential is measured against the Standard Saturated Calomel Electrode (SCE) as per the standard test procedure. The $\mathrm{CP}$ experiment was continued and the periodical data was collected over a period of 250days. At the end every tenth day the following data were collected and recorded.

1. Potential of steel rebar using pre calibrated SCE

2. Polarized potential (potential shift) of steel during $\mathrm{CP}$

3. Galvanic current flow

4. Concrete resistivity

The polarisation shift was measured by disconnecting the anode and rebar terminals the potential decay is measured for a period of 250days. The galvanic current densities are calculated by measuring the current flowing across the resistor. The concrete resistivity is measured using the four probe resistivity method. Cathodic protection criteria were evaluated using gravimetric weightloss methods.

\section{Results and Discussion}

Figure 1. Represents the potential- time behaviour of steel embedded in concrete slab in chloride free and chloride contaminated concretes labs over a period of 250 days of exposure. It is observed that initially the potential of steel is less negative and then moves towards more negative values. In the case of chloride free concrete slabs, the potential of steel is measured as $-175 \mathrm{mV} \mathrm{Vs.SCE}$ at the end of 250 days of exposure. As per the ASTM standard the steel rebars are in passive condition because of high alkalinity of concrete around the steel. Similarly in the case In the case of chloride contaminated concrete slabs, the potential of steel is measured as $350 \mathrm{mV}$ at the end of 250 days of exposure, which represents the steel rebars are in highly active condition due to the corrosion acceleration by active chloride ions present in the concrete slabs.

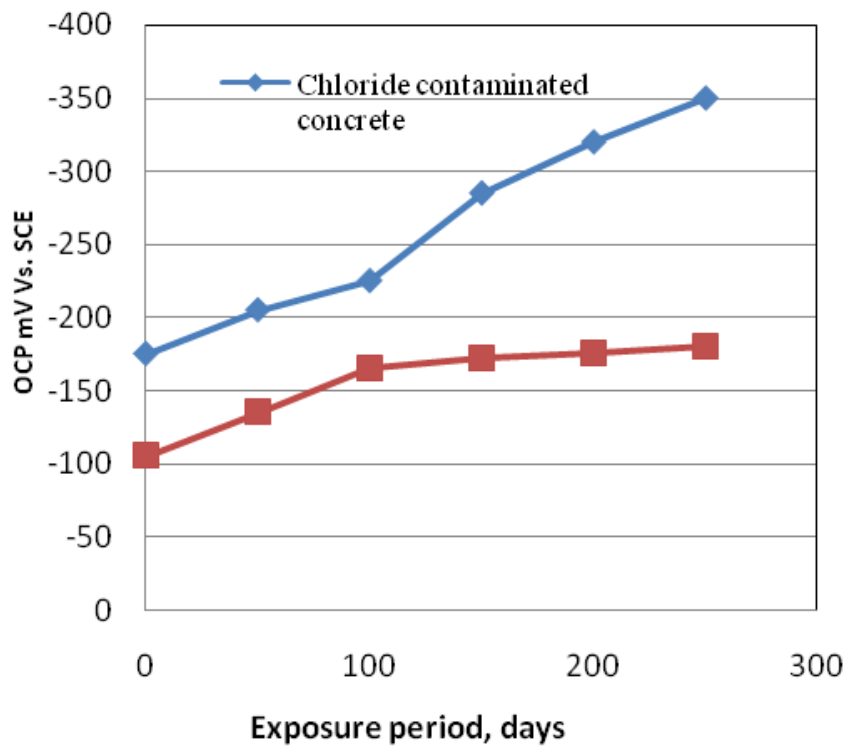

Fig. 1: Potential-time behaviour of embedded steel in concrete slab

Figure 2.Represents the concrete resistivity-time profile for concrete slabs in chloride free and chloride contaminated concretes over a 
period of 250 days of exposure. It is observed that initially the concrete resistivity is measured as low as $10 \mathrm{~K} . \mathrm{Ohm} . \mathrm{cm}$ then it increased to $50 \mathrm{~K}$.Ohm.cm at the end of 25odays of exposure for the chloride free concrete slabs. Similarly in the case In the case of chloride contaminated concrete slabs, the concrete resistivity is measured as high as $25 \mathrm{~K} . \mathrm{Ohm} . \mathrm{cm}$. This trend is quite obvious because of the increased conductivity (i.e. reduced resistivity) by the chloride ions present in the concrete slabs. So the corrosion probability is high in the low resistance concrete and hence the steel rebars showed corroded condition.

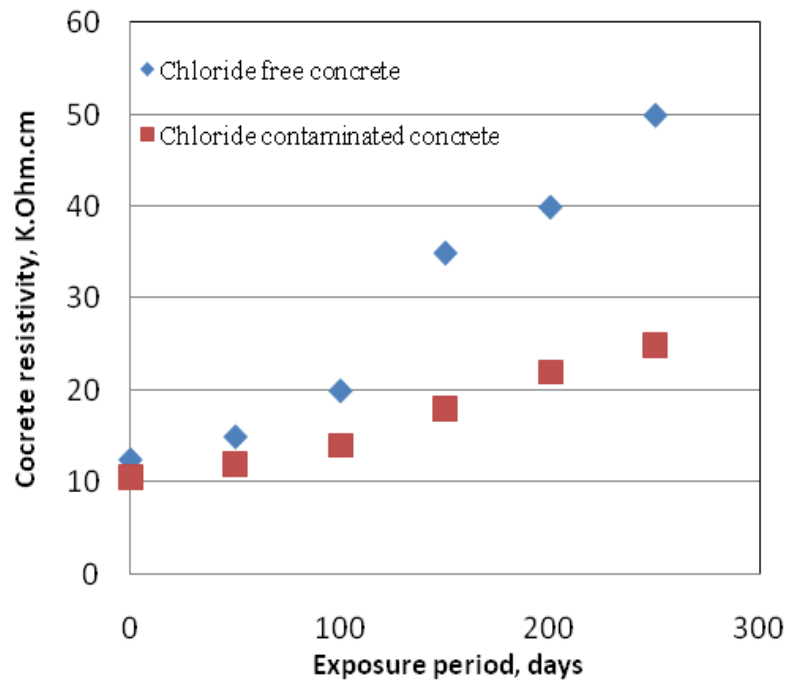

Fig. 2: Concrete resistivity-time profile for experimental specimen

Figure 3.Shows the polarisation shift-time profile for steel embedded in chloride free concrete and chloride contaminated concrete over a period of 250days of exposure. It can be seen that in all over the region, the potential of steel has got shifted in the cathodic direction and the polarised potential is measured as $350 \mathrm{mV}$. This is attributed to the cathodic protection, which has shifted the potential of steel by about $200 \mathrm{mV}$ (OCP is $-125 \mathrm{mV}$ ) in the chloride free concrete slab. Similarly in the case of chloride contaminated concrete, the polarised potential is measured as $400 \mathrm{mV}$, which shifts the steel potential to $300 \mathrm{mV}$. According to the CP criterion evaluated by the famous author Takawaka, the $100 \mathrm{mV}$ is necessary for the protection of steel rebars embedded in chloride free concrete. So the potential shift is higher than the recommended criteria, exhibits effective performance of galvanic protection using ribbon type zinc anode [21].

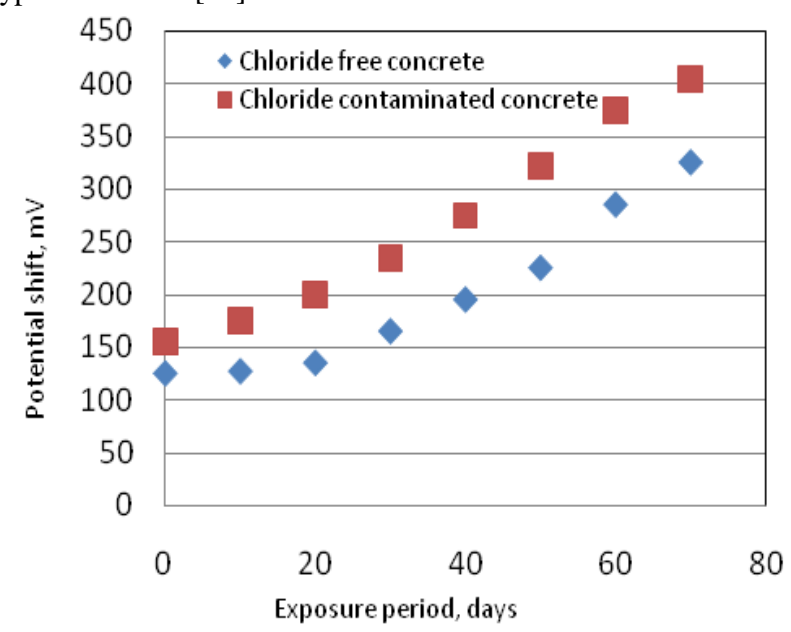

Fig. 3: Potential shift-time profile for galvanically protected concrete slab
Figure 4.Shows the galvanic current flow-time profile on chloride free concrete over a period of 250days of exposure. It is observed that initially a higher galvanic current density of $100 \mathrm{~mA} / \mathrm{m}^{2}$ is found to flow and it is stabilised as $50 \mathrm{~mA} / \mathrm{m}^{2}$ at the end 250 days of exposure. Normally $10 \mathrm{~mA} / \mathrm{m}^{2}$ is a recommended current density for the protection of steel rebars embedded in chloride free concrete. Further it is observed that initially a higher galvanic current density of $150 \mathrm{~mA} / \mathrm{m}^{2}$ is found to flow and it is stabilised as $75 \mathrm{~mA} / \mathrm{m}^{2}$ at the end 250 days of exposure as in the case of chloride contaminated concrete slab. The higher galvanic current is due to the increased conductivity by the chloride ions present in the concrete slabs.

\subsection{Analysis of CP Criterion for Cathodic Protection of Steel in Concrete}

Figure $4 \& 5$ Shows the results of evaluation of CP criterion for cathodic protection of steel embedded in concrete slabs in chloride contaminated as well as chloride free concrete slabs over a period of 250 days of exposure. It can be seen that a negligible corrosion rates (metal loss) are obtained when the potential shift is found in the range of 100 to $150 \mathrm{mV}$ in the chloride free concrete. Hence the 100 to $150 \mathrm{mV}$ is evidenced for the $\mathrm{CP}$ criteria for steel rebars embedded in chloride free concretes. Similarly in the case of chloride contaminated concrete, negligible corrosion rates are obtained when the potential shift is found in the range of 150 to $200 \mathrm{mV}$ evidenced for the CP criteria for steel rebars embedded in chloride contaminated concretes[22]. This experimental criteria are found well agree with the standard potential shift recommended for effective protection of embedded steel. Obviously, the recommended potential criteria are necessary for maintaining the passive state of the steel rebar in both the condition.

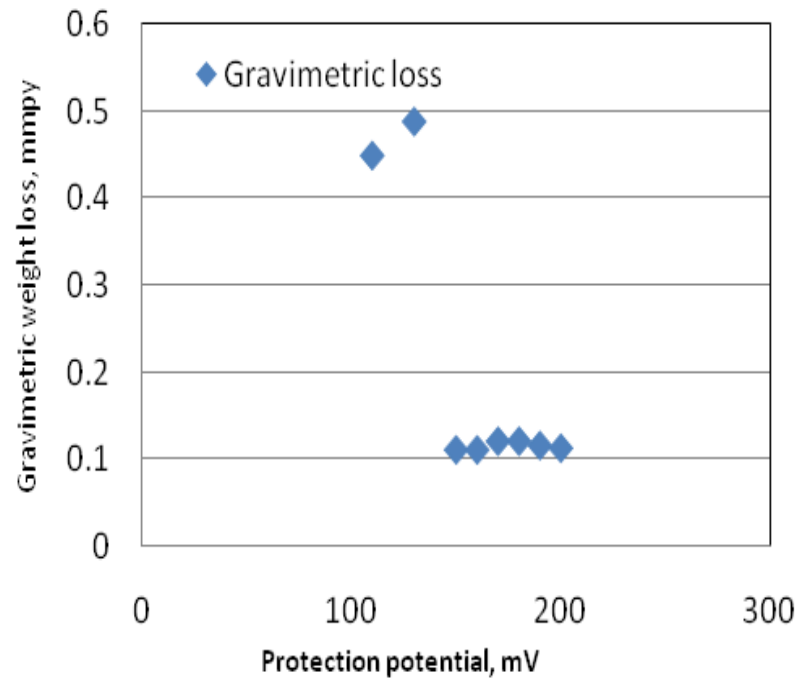

Fig. 4: Evaluation of CP criterion for cathodic protection of steel in chloride contaminated concrete slab 


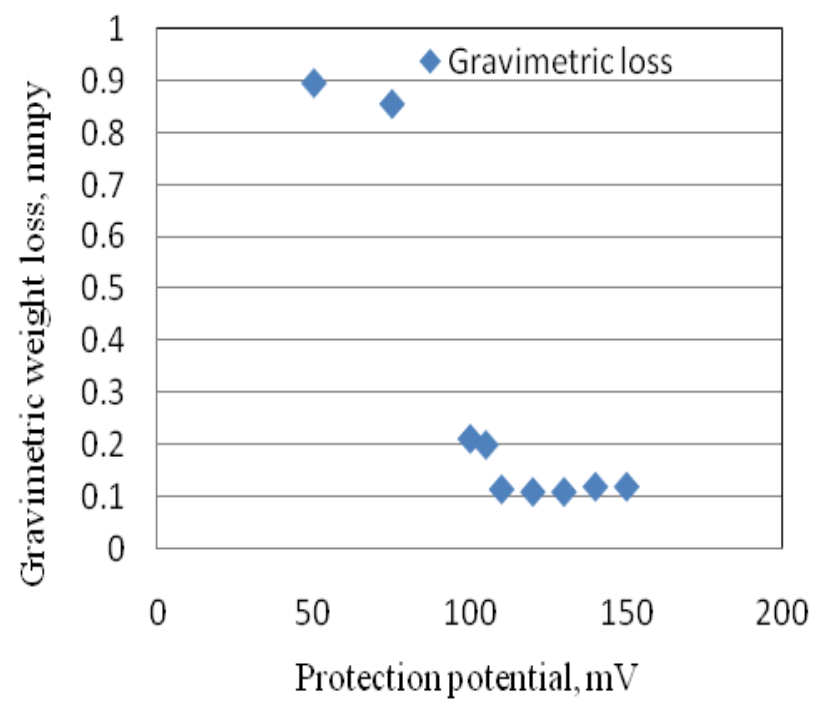

Fig. 5: Evaluation of $\mathrm{CP}$ criterion for cathodic protection of steel in chloride free concrete slab

\section{Conclusion}

The following conclusions can be drawn from the present investigations:

The use of ribbon type zinc sacrificial anode with ion conductive polymer backfill is able to ensure the effective cathodic protection of steel rebars in concrete over a period of time. The newly developed ion conductive polymer backfill is able to perform an effective electrochemical interface in cathodic protection of steel in concrete over the period of study.

\section{Acknowledgement}

The Authors would like to thank the Government of India for financial support given to our prestigious institution Veltechmultitech Dr.Rangarajan Dr.Sakunthala Engineering College, Chennai (A constituent Institute of Veltech group of Organisation) under DST-FIST program, New Delhi. The authors also extend their gratitude to the Management, Veltechmultitech group of Institutions, Chennai for their active support to carry out the work successfully.

\section{References}

[1] Page C.L., Cathodic Protection of Steel in Concrete-Principles and applications. Proceeding of international conference on Repair of Concrete Structures theory and practice in a Marine environment, Solver (Norway), Vol.28-30, 1997, pp. 123-13.

[2] Pedeferri P, Cathodic protection of new concrete construction. In. Proceedings of the international Conference on Structural Improvement through Corrosion Protection of Reinforced Concrete, Institute of Corrosion, London 1992.

[3] Bertolini L, Bolzolini L, Pastore T and Pedeferri P, New experiences in Cathodic Prevention of reinforced Concrete Structures. In: C.L.Page et al Corrosion of Reinforced Concrete, Society of Chemical Industry, London 1996.

[4] Bertolini L, Bolzolini L, Pastore T and Pedeferri P, Three Year Test on Cathodic Prevention of reinforced Concrete Structures, International Conference on Corrosion, Corrosion 97, 1997, paper 244, NACE, Houston.

[5] Standard EN 126696-1, Cathodic Protection of Steel in Atmospherically Exposed Concrete, March 2000.
[6] Glass GK, Analysis of data on Reinforced Concrete Cathodic Protection System', Material Performance, Vol.35, No. 3, 1996, pp.29-35.

[7] Eons D.G., Williams A.J and Scrully J.R, Long-term effect of Cathodic protection on pre-stressed concrete Structures-Hydrogen Embrittlement of Prestressing Steel' Corrosion Journal, Vol.53, No. 11, 1997, pp.891-908.

[8] Hassanein A.M., Glass G.K and Buenfeld N.R., Effect of Intermittent Cathodic Protection on Chloride and Hydroxyl ion concentration Profiles in reinforced concrete' British Corrosion Journal, Vol. 34, No.4,1999, pp254-261.

[9] Robert Brown P and John Tinnea S. Cathodic Protection design Problems for Reinforced concrete', Materials Performance, Vol.30, No.8, 1991, pp 28-31.

[10] Sagues and Krane S.C., Determination of Polarisation Diagrams of Reinforcing Steel in Concrete' Corrosion, Vol.48, 1992, No.8, pp.624633.

[11] De Rincon OT, De Romero D.M et al., Corrosion Monitoring of Steel reinforcement bars in concrete environment, journal of Material Structures', Vol. 30, 1997, pp. 556.

[12] Krane S.C, Sagues A.A, Presuel Moreno F.J, Computational and Experimental investigation of Cathodic Protection current distribution in reinforced concrete of Marine Piling, Corrosion 97, 1997, pp 231.

[13] Sagues A.A, Krane S.C and Presuel Moreno F.J and Silva Araya W.I, Advanced Computational Model for Sacrificial Cathodic Protection of submerged reinforced concrete Marine Footers. Repair and Rehabilitation of Reinforced Concrete Structures. The State of the Art, American Society of Civil Engineering, Reston, 1997, pp. 1-13.

[14] Glass G.K and Buenfeld N.R. (2002), 'Influence of Chloride Binding on the Chloride Induced Corrosion Risk in Reinforced Concrete', Corrosion Science, Vol. 42, 2002, No. 2, pp. 329-344.

[15] Chang J.J. A Study of the bond Degradation of Rebar due to Cathodic Protection Current, Journal of Cement and Concrete Research, Vol. 32, 2002, pp.657-663.

[16] Metwally et al, Factors affecting Cathodic Protection Interference, Journal of Engineering Analysis with Boundary Elements, vol. 31, No. 6, 2007, pp. 485-490.

[17] Effect of Intermittent Cathodic Protection on Chloride and Hydroxyl ion concentration Profiles in reinforced concrete' British Corrosion Journal, Vol. 34, No.4, 2006, pp254-261.

[18] Andrade $\mathrm{M}$ et al and Welde B.E., Control of Cathodic Protection in Bridges without disconnecting protection current: Passivity verification Technique (PVT) Journal of Corrosion Engineering, Science and Technology.Vol.42, No. 3, 2007, pp. 215-223.

[19] Bertolini et al., Effects of Cathodic Prevention on the Chloride Threshold for Steel Corrosion In Concrete, Journal of Electrochemical Acta, Vol. 54, No. 5, 2009, pp. 1452-1458.

[20] Persa M.H.et al, Simulation of Cathodic protection Potential Distribution on Oil well casings, Journal of Petroleum Science and Engineering, Vol. 72, No. 4, 2007, pp 215-219.

[21] Ken pit house, A review of Cathodic Protection Systems Currently available to combat rebar corrosion caused by chloride ingress in concrete, Anti-corrosion Methods and Materials, 1997, Vol. 34, No. 8 , pp. 12-13.

[22] National Association for Corrosion Engineers (NACE) standard, Houston, Texas Cathodic Protection of Reinforcing steel in Atmospherically Exposed Concrete Structures, REPORT No. 290, 1990, pp. 268-278. 